\title{
Personalized Education: Analog of Personalized Medicine?
}

\author{
Wendy Johnson* \\ Department of Psychology, University of Edinburgh, UK
}

Submission: August 23, 2017; Published: September 06, 2017

*Corresponding author: Wendy Johnson, Centre for Cognitive Ageing and Cognitive Epidemiology and Department of Psychology, University of Edinburgh, 7 George Square, Edinburgh EH8 9JZ UK, Tel: +44 (0)131 651 1304; fax: +44 (0)131 650 3461; Email: wendy.johnson@ed.ac.uk.

\begin{abstract}
This chapter discusses the role of genetically influenced normal-range intelligence in educational achievement and attainment. I suggest that there is evidence that we have developed an educational system that reinforces genetic disadvantage contributing to low educational achievement and genetic advantage contributing to high educational achievement through the presence of gene-environment correlation. Though no one would want to stifle high achievement in the most capable students, we need to work to foster achievement in the least capable. This likely means working towards educational programs that more clearly recognize individual differences in ability. This is fraught with political and practical difficulties in implementation.
\end{abstract}

Keywords: Education; Genetic influences; Intelligence; reading

\section{Introduction}

This chapter discusses the role of genetically influenced normal-range intelligence in educational achievement and attainment. By normal-range intelligence, I mean intelligence as commonly measured by standard tests of intelligence such as the Wechsler scales, in individuals with no diagnosis of learning disability. Such tests are generally considered to reflect the ability to absorb and make use of cognitive, conceptual material. The kinds of material presented in most educational curricula are good examples of this, but they are far from the only such examples.

\section{Some Background on the Genetics of Intelligence}

Intelligence as measured in this way is one of the most reliably measured behavioral traits. It is also measured with great validity, as scores on intelligence tests show substantial associations with educational achievement and attainment, occupation, job performance, income, socioeconomic status, and even health and mortality Gottfredson, 2007; Gottfredson \& Deary, 2004. Moreover, rank-order correlations of scores tend to be high, indicating that relative levels of intelligence are highly stable over time Deary, Whiteman, Starr, Whalley, \& Fox, 2004; Moffitt, Caspi, Harkness, and Silva [1] . Even within normal ranges, among people not considered to have any form of learning disability, it shows considerable variability, with IQ scores within two standard deviations of the mean ranging from 70 to 130 . Intelligence shows substantial genetic influences as well; heritability estimates range from about $30 \%$ in early childhood to about $80 \%$ in adulthood Plomin, De Fries, McClearn, and McGuffin, [2].

In addition, correlations among specific aspects of cognitive ability are genetically mediated, as are intelligence's developmental stability and correlations among biomarkers of intelligence such as gray and white matter density, brain volume, and inspection time. Despite this and many investigations, at this time we have not identified any specific genetic loci associated with normal-range intelligence Deary, Johnson, and Houlihan [3]. As with many other quantitative traits for which the situation is similar, this suggests that the genetic influences on intelligence derive from many genes of very small effect. It also suggests that there is considerable redundancy in the specific genes that can contribute to intelligence and that the same level of intelligence can develop through the presence of many different combinations of these genes of very small effect, some of which may be expressed in some environmental circumstances but not others, and/or the presence or absence of some other genes but not others. 
The genetic influences on intelligence show a particular developmental pattern that is well established Plomin, De Fries, McClearn, and McGuffin [2]. In early childhood, they account for a little more than $30 \%$ of variance, with shared and non shared environmental influences accounting for similar proportions of variance. With increasing age, genetic influences account for steadily increasing proportions of variance, growing to as much as $80 \%$ in adulthood. At the same time, shared environmental influences account for steadily decreasing proportions of variance, becoming negligible in adulthood.

Of course intelligence is not measured with much accuracy in very young children, but accuracy increases with age. Because non shared environmental influences include measurement error, non shared environmental influences also account for decreasing proportions of variance with age, though they still account for about $20 \%$ of variance in adulthood. The way in which these estimates are made, however, relies on the assumption that genetic and shared and non shared environmental influences are independent of each other. This independence assumption is tenuous.

There are two major ways in which the independence assumption may be violated. First, genetic and environmental influences may interact. Gene-environment interaction occurs when individuals carrying different genes are differentially sensitive to environmental circumstances. We all recognize such situations, though perhaps not by that name, For example, some people's skin burns readily in the sun, while others' does not. That is, the presence of strong sunlight causes expression of genes associated with skin inflammation in some people but not others. The specific genes being expressed differently do not have to be genes which vary among humans, however; it may be that genes that do not vary in humans are regulated in expression in the relevant environment by others that do. The second major way in which the independence assumption may be violated is through gene-environment correlation. This occurs when there are genetic influences on exposure to environmental circumstances. The result of this is population genetic stratification, or different gene frequencies among people in different environmental circumstances. The possibility that such genetic stratification exists in the population is politically unpalatable and thinking about it makes many people very uncomfortable, yet the possibility is very real.

There are three major ways in which gene-environment correlation may take place. It may be passive, as when more educated, brighter parents pass their genes for high intelligence to their children and also tend to engage them in more intellectually stimulating activities than do less educated, less bright parents. Gene-environment correlation may also be evocative, as when teachers see that a child is bright and interested, and offer encouragement in pursuing further activities. It may also be active, as when the bright child herself seeks out additional reading material or spends otherwise free time practicing a musical instrument or doing science experiments.
In the world in general, gene-environment interaction and gene-environment correlation are linked Johnson [4]. Humans are mobile organisms and always have at least some choice about the kinds of activities in which they engage. Thus they have some control over the environments they experience. Some of this control is exerted through physical movement, but even behavior is a way of selecting one's environment because behavior tends to elicit responses from others, with different behaviours eliciting different responses and thus different environmental consequences. When faced with adverse circumstances, people move to avoid them, and when presented with attractive opportunities, people move toward them.

Movement may be elicited through genetically influenced sensitivity to the environmental circumstances, and those most sensitive to the any specific environmental circumstance will be, all else equal, most likely to move first. Thus, for example, those with skin most likely to burn in the sun will be more likely to be careful about using sunscreen, limiting time in the sun, and/ or wearing protective clothing. But ability to move is often not completely free, and some may have more ability to move than others. All else being equal, those most able to move will likely move first.

For example, people who work as lifeguards or fruit pickers may not be able to limit time in the sun. Of course movement may also be constrained by conflicts in goals. People very vulnerable to sunburn may still take jobs as lifeguards or fruit pickers because they need jobs or because they have reasons to acquire certain kinds of experiences in order to meet other goals. In the presence of interaction between genetic and shared environmental influences, standard estimates of genetic influence based on the independence assumption are overstated Purcell [5]. Such estimates are also overstated in the presence of correlation between genetic and non shared environmental influences, but they are understated in the presence of correlation between genetic and shared environmental influences.

Thus, one way to explain the robust observation that genetic influences on intelligence increase with age while shared environmental influences decrease is to suggest that about $30 \%$ of the variance in intelligence may be caught up in correlation between genetic and shared environmental influences in childhood that gradually shifts to correlation between genetic and non shared environmental influences in adulthood, as children grow up and leave home. The really provocative possibility is that some of this shift may be driven by interaction involving long-term differences in gene expression driven by shared environmental circumstances that have effects on level (means) as well as variance. Intelligence definitely shows some norm of reaction, or flexibility of phenotypic expression in different environmental circumstances, though how much is unknown. I suspect, however, that it may be on the order of 20 points, which is huge within the population. 


\section{Implications of the Genetics of Intelligence for Education}

The facts about the genetics of intelligence have some important implications for education that we tend to see played out in the society around us. First, all else being equal, the most capable students will tend to seek the most education, because they find the process rewarding (they are good at it). Again all else being equal, they will also tend to get the most out of whatever education they receive, because they are able to process the material presented more rapidly and thoroughly and to retain it better. Of course all else is rarely equal, but the reverse is true as well: those least capable will be most likely to quit education as soon as they are allowed, and will tend to get less out of whatever education they receive, often at least partly because they lack motivation because they find the process of education unpleasant environment correlation will tend to create or accentuate population stratification for genetic influences on intelligence because occupations differ considerably in educational requirements and demands for intellectual skills.

As a society we can take policy actions to counteract these tendencies, but the questions are just what sorts of actions should we take, how much will they cost, and will they be effective. Many intervention programs intended to raise intelligence in disadvantaged preschool children have been tried, ranging in scope from Head start at the national level in the United States to the Perry Preschool Project in one small town in Michigan. The results, however, have not been particularly encouraging. Though children show reliable gains in the short term, the gains tend to fade within a year or two Pianta, Barnett, Burchinal, \& Thornberg [6]. Some gains do persist: children who participated in such programs tend to be somewhat more likely to finish high school and to function somewhat more responsibly as adults.

We also know from studies of children on either side of some arbitrary school entrance cut-off such as birth date that those who have received an additional year of education do tend to score somewhat higher on intelligence tests. Moreover, adoption from parents in disadvantaged circumstances into families in better socioeconomic circumstances tends to produce IQ gains on the order of perhaps 12 points Nisbett 2010; though there is little evidence about the retention of these gains in adulthood), and something is causing the Flynn Effect Flynn [7], or the robust observation that IQ test scores tended to increase about 3 points per decade throughout the $20^{\text {th }}$ century. The No Child Left behind Act in the United States was designed to address exactly this issue, of course, but it is far from clear that the law is effective.

We can also take curricular actions to counteract the tendency for gene-environment correlation to accentuate social stratification for genetic influences on intelligence. There is no question that attitudes and motivation toward education are important above and beyond intelligence in fostering educational achievement. One of the ways in which they matter is in how children think about the associations among ability, effort, and outcomes. When children think that ability is fixed and they only have so much of it, they may tend to view un favourable achievement outcomes as indications that they simply did not have enough ability, which tends to reduce their motivation to keep on trying. In contrast, when children think that performance is a result of effort and that they can build skills and abilities over time through work and practice, the often tend to view unfavourable achievement outcomes as indications that they did not try hard enough and they should try harder next time. Empirical studies confirm the common-sense supposition that cumulative achievements tend to be higher among those with the latter attitude, and that this attitude can be taught Blackwell, Trzesniewski, Dweck, 2007.

\section{Using Quantitative Genetic Modelling to Think About Educational Policy Goals}

Societies tend to have two in some ways contradictory goals in providing public education. The first goal is to build a citizenry with the intellectual skills required to function responsibly as citizens and in managing their own lives and finances, but also to build a workforce that has the skills necessary to drive the economy, including providing economic growth. As the economies of most western countries have moved from manufacturing to service bases over the last 50-60 years, there have been massive increases in the intellectual skills required, and the proportions of the population entering tertiary education have grown dramatically.

It is far from clear that the educational system in the United States has succeeded in meeting the needs of its society, as many students enter tertiary education without the necessary skills, and many institutions that hire highly skilled technical workers rely on candidates from other countries. This relates to the second goal of public educational systems, which is to provide opportunities for each individual to reach his/her educational potential. The two goals come into conflict because resources for education are always finite, and the educational needs of those of most and least ability tend to be very different from each other and from those of students of average ability. To the extent that we devote resources to making sure that everyone reaches some minimal level of education, we may not be able to meet the special needs of the most capable students, and vice versa.

The large population variance in intelligence, or learning and reasoning capacity, and its apparent genetic influences, introduces complexity in thinking about measuring the impact of changes or differences in educational quality. Most people are very used to thinking of change or difference in achievement in terms of mean levels. Figure 1 shows the way in which people often assume changes or differences are manifested: variance in achievement is constant throughout the range of educational quality and the only effect of change or difference is on the mean level. 


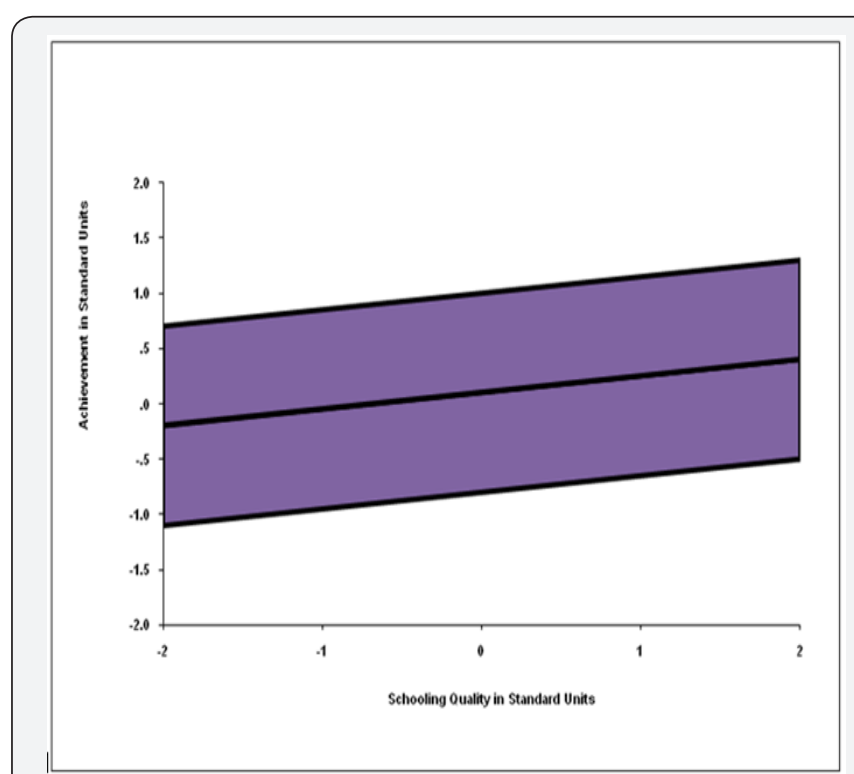

Figure 1: Uniform Effect of Schooling Quality.

But change or difference in mean levels is almost always accompanied by changes or differences in variance as well, and changes or differences in variance may tell us even more about the extent to which we are meeting the two goals of public education than those in means. For example, some kinds of improvements in educational quality may primarily prevent low achievement by devoting additional resources to the least capable students. Such a program might generate results such as those shown in (Figure 2), in which variance at the low end of achievement is reduced, resulting in overall mean level increases in achievement. This result would be considered successful from the perspective of building an educated citizenry, but might not be considered so successful from the perspectives of providing a workforce with all the necessary skills and helping all students to reach their intellectual potentials, given the stagnation or even decrease in top-end achievement at the highest level of educational quality.

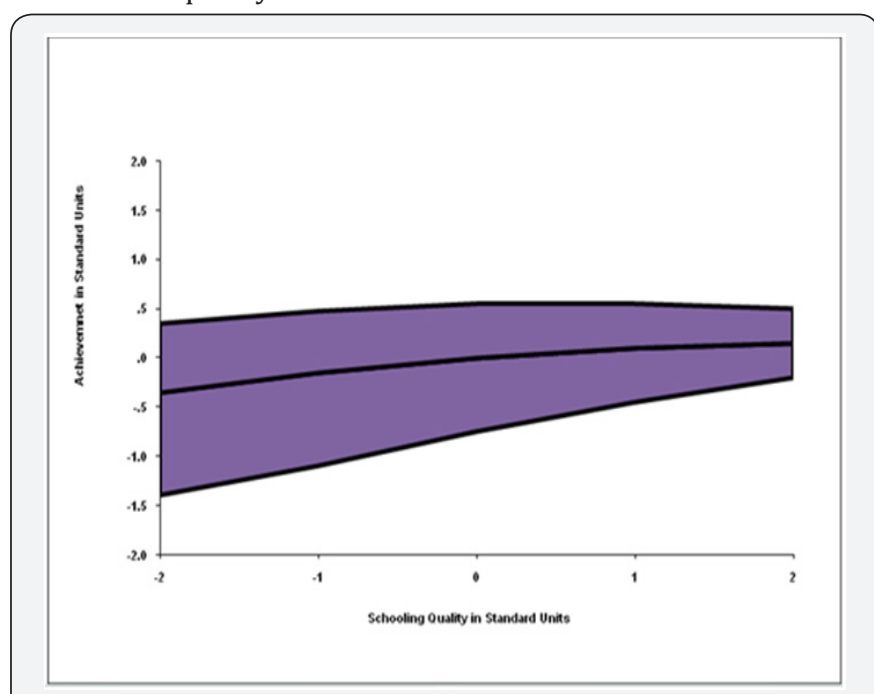

Figure 2: Good Schooling Allows Low Achievement.
In contrast, other kinds of improvements in educational quality might primarily stimulate greater achievement among the already most capable students, perhaps by offering enrichment programs to students identified and gifted and talented. Such a program might generate results such as those shown in (Figure 3 ), in which variance at the low end of achievement remains constant but variance at the high end of achievement increases as the most capable students gain the most from the enrichment, again resulting in overall mean level increases in achievement.

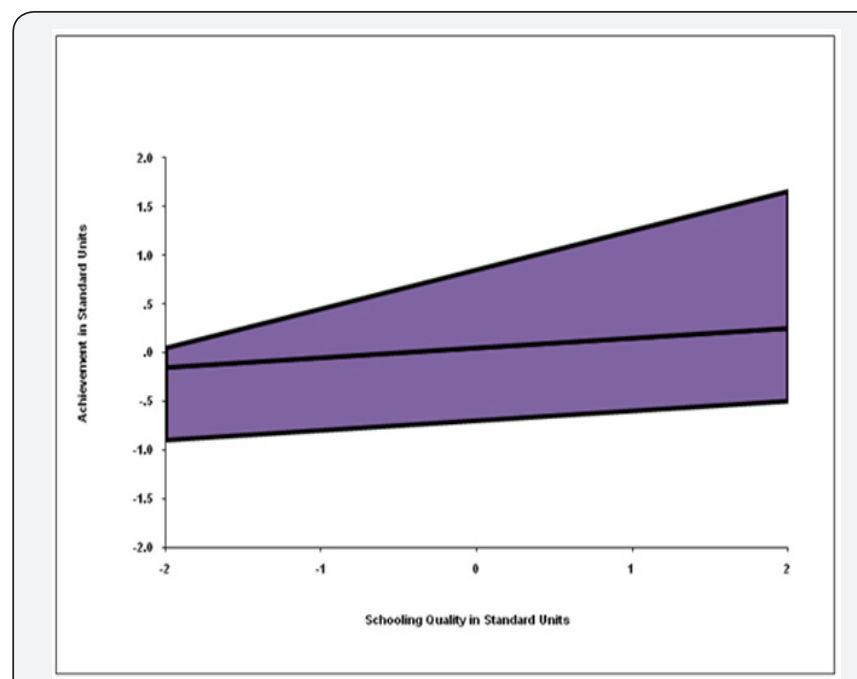

Figure 3: Good Schooling Allows Flowering of Achievement.

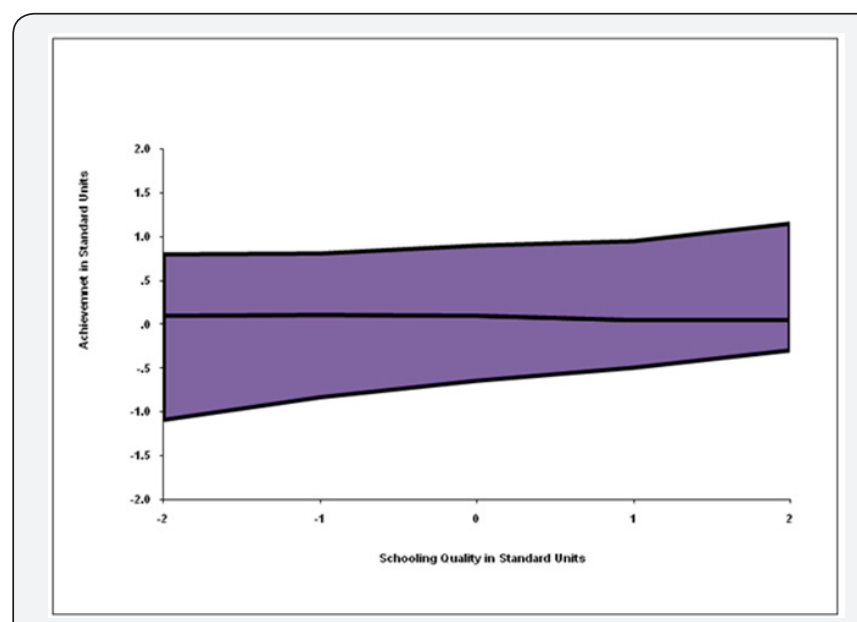

Figure 4: The Idea?

This result would be considered successful in building a workforce with the necessary high-level skills and knowledge and helping the 'best and brightest' to reach their intellectual potentials, but might not be considered so successful in eliminating or reducing the numbers who do not reach a level of education needed to be responsible and productive citizens. Perhaps the ideal is as shown in (Figure 4), but this may entail very different kinds of educational programs for the most and least capable students. Such tracking always raises many political issues, Because of its focus on variance, quantitative genetic modelling can be particularly helpful in revealing many 
factors moderating associations between existing variables that might help guide us in developing ideas about how to achieve desirable changes.

They can do this by showing whether current circumstances more closely resemble (Figure 1-3), or some other pattern. And, by comparing patterns in different areas that have different educational systems and circumstances, we can get some idea of how patterns might change if we were to make changes in our educational system and policy.

\section{A Study Using this Kind of Quantitative Genetic Modelling to Study Learning Environment}

Several studies have provided this kind of information. One was conducted using data from Florida students and so is particularly relevant there Taylor, et al. [8]. The study was based on 280 monozygotic and 526 dizygotic first- and second-grade twins in the Florida Twin Project on Reading, a sample that represents the ethnic, geographic, and socioeconomic diversity of the state. Their reading achievement was measured using the Oral Reading Fluency test Good, Kaminsky, Smith, Laimon, \& Dill [9], administered towards the end of the school year.

Teacher quality was measured by average growth in reading achievement of the twins' classmates during the year. The twins in the sample were typical of their classmates: those in classes gaining in oral reading fluency two standard deviations below the mean gained on average only 11 points on the test, while those in classes gaining two standard deviations above the mean gained on average 125 points on the test, with a steady progression of gains for those in classes in between. (Figure 4) shows the reading model used. Under the model, variance in oral reading fluency attributable to genetic and shared and non shared environmental influences was allowed to differ linearly with level of teacher quality as measured.

Results indicated that neither shared nor non shared environmental influences on oral reading fluency differed with level of teacher quality. Genetic influences, however, were higher with level of teacher quality, roughly doubling over a 4-standard deviation range of teacher quality. This suggested that environmental associations with teacher quality, or perhaps more accurately learning environment, were direct as shown in (Figure 1). Relative to the average prevailing learning environment, however, poor learning environments were associated with suppressed genetic influences, and good learning environments were associated with enhanced expression of genetic influences.

Thus, the nice main effect could be attributed to both the supportive effects of better learning environments and enhanced genetic response to it, resembling the situation in (Figure 3). Because of this, heritability of oral reading fluency ranged from less than $30 \%$ in the the poorer learning environments to over $50 \%$ in the better ones. Genetic correlations between teacher quality and oral reading fluency were low and not significant.
This was likely because the children did not select their own learning environments. The shared environmental correlation was constant across the range of teacher quality at .96, which was highly significant. This suggests that families with the best students gravitated to the schools with the best learning environments. The nonshared environmental correlation was significant as well, though much smaller at .22. This suggests that, even within families, there is some tendency for the better students to wind up in better learning environments.

In these young children, the learning environment appeared to have been rather important to their gains in oral reading fluency, especially because good learning environments appeared to allow the flowering of genetic potential, while poor learning environments suppressed it. The strong shared environmental correlation suggested substantial social stratification in learning environments, with better students getting better environments. This social stratification was manifested at the level of the family, suggesting that better-educated parents were congregated in the areas feeding into schools with better learning environments, and vice versa. Reducing the extent to which this is true may be desirable to improve educational outcomes for low-achieving students, but it will not be popular (or likely desirable) if it results in slower achievement gains in high-achieving students.

\section{Some Studies Using this Kind of Modelling to Study Individual-Level Contributions to Achievement}

This particular study offered little insight into how the individual child contributes to his/her educational development, partly because the children in the sample were so young, and partly because the moderating variable, teacher quality or learning environment, was measured at the level of the classroom. Another study, using somewhat older children and intelligence as the moderating variable, provided some hints about this Johnson, Deary, \& Iacono [10]. Using the same basic model as for the Florida reading study described above, this study examined how IQ measured at age 11 moderated genetic and environmental influences on grade point average (GPA) in 17-year-old twins from the younger cohort of the Minnesota Twin Family Study, and how IQ measured at age 17 moderated genetic and environmental influences on educational level attained (high school, post-high school vocational training, college, graduate-levle training, on a 12-point scale) in 24-yearold twins from the older cohort.

Again, there were substantial main associations of earliermeasured IQ with later-measured achievement: the correlation between age 11 IQ and age 17 GPA was .40, and that between age 17 IQ and age 24 educational attainment was .32. Results for the younger cohort were quite different than those for the Florida reading study. This does not indicate inconsistency or failure to replicate, however, as the moderating variable, IQ, in this study was so different from teacher quality or learning environment. In this study, there were no differences in genetic or shared environmental variance with level of IQ, but non 
shared environmental variance was substantially lower among those with higher IQs.

In fact, non shared environmental variance ranged from more than .55 to less than.10 across the 4-standard deviation span from 2 standard deviations below mean IQ to two standard deviations above. This suggested that the genetic and shared environmental associations between IQ and GPA were direct: adolescents were using their genetic and familial backgrounds to improve their GPAs. It also suggested that these backgrounds, when favourable, were robust: the kinds of relatively stochastic events encompassed by non shared environmental influences appeared to have little influence.

Perhaps even more optimistically, because these influences were greater among those with low IQ, not all of them were doing poorly. The genetic correlation of 62 supported the interpretation that students were using their genetic backgrounds to improve their GPAs. Neither environmental correlation, however, was significant. A possible explanation of the absence of shared environmental correlation might be that one of the ways both mono- and dizygotic twins form individual niches for themselves within their pair ship is by drawing contrasts between their perceived abilities and performing accordingly, within their common school environments.

The idea that common genetic and familial background has lasting effects on mean levels of school achievement also reverberated in the results from the older Minnesota Twin Family Study cohort. As in the Florida reading study, genetic influences on variance in educational attainment were much greater when IQ was high than when it was low, approximately tripling across the four-standard deviation range of IQ from two standard deviations below the mean to two standard deviations above. In contrast to the situation with GPA in the younger cohort, there were no differences in the extent of non shared environmental variance on educational attainment.

But shared environmental variance showed a pattern directly opposite to, and more extreme than, that of genetic variance: shared environmental variance was over .9 at two standard deviations below mean IQ, and only about .1 at two standard deviations above mean IQ. This meant that, when IQ was high, so was heritability of educational attainment. But when IQ was low, educational attainment was primarily attributable to shared environmental influences. Moreover, the genetic correlation between IQ and educational attainment was rather strong, .62, when IQ was low, but only .28 when IQ was high.

The shared environmental correlation was 1.00 throughout the range of IQ, and the non shared environmental correlation was 0 . This suggests that low IQ acted as a barrier to high educational attainment, probably in particular university admission, but that this barrier could be overcome by shared environmental influences, probably especially parents who were willing and able to pay for university admission wherever the student could manage it. Interestingly, among those with high IQ, the genetic variance in educational attainment was not strongly associated with that on IQ, suggesting that other genetically influenced traits such as personality, motivation, and interest contributed.

Shared environmental influences common to IQ and educational attainment did not contribute to variance in educational attainment, but the fact that they were linked suggests that may have contributed to the association between IQ and educational attainment. The results of these studies were rather dissimilar, but there is no reason to think they should have been similar, as the moderating and outcome variables were not the same. Still, we should be able to use them to gain some understanding of the ways in which genetic and family and other environmental influences contribute to educational outcomes.

Given the wide disparities in achievement levels from school district to school district and the often substantial need for remedial classes among entering university students, one interpretation consistent with the results of all three studies is that, in the United States, there is considerable social stratification by both IQ and family culture emphasizing educational attainment, with people sharing both greater academic aptitude and values surrounding achievement tending to send their children to better schools. These students then get good starts in reading and other basic academic skills, and go on to use these skills to build further skills at the next academic level.

The presence of these skills, and likely the confidence that their mastery brings with them, helps to buffer these children from vagaries or less-than-optimal environmental experiences at any one level. And individual children from such families who do not have high IQs can often still reach high educational attainment through parental support. On the other hand, low IQ and family background that does not support educational attainment, whether culturally or do to lack of financial resources, can act as a barrier to high educational attainment.

\section{What about Other Places and Cultures?}

The final study I will discuss was carried out using very similar data on IQ and educational attainment from the Swedish Twin Registry Johnson, Deary, Silventoinen, Tynelius, \& Rasmussen [11]. Results for genetic variance were very similar to those in the Minnesota data: among those with IQs two standard deviations above the mean, genetic variance in educational attainment was about twice that among those with IQs two standard deviations below the mean. The Swedish sample was much larger than the Minnesota one, and this allowed for a small effect of IQ on non shared environmental variance in educational attainment as well: it was slightly greater in those with high IQs than in those with low IQs.

What was particularly striking, however, was the difference between the Swedish and Minnesota results for 
shared environmental influences. While in Minnesota, shared environmental influences on educational attainment were strong when IQ was low and weak when it was high, the opposite was the case in Sweden: shared environmental variance was weak when IQ was low and strong when it was high, the same pattern as both studies showed for genetic variance. Genetic correlations were. 53-56, the shared environmental correlation was 1.0 at all levels of IQ, and the non shared environmental correlations were significant at. 14-.16.

All sources of variance worked in concert, and there was much less overall variation in attainment at the low end of IQ than at the high end. Sweden's educational system and social structure differ from those in the United States in ways that probably contributed to the differences in results. There is a national curriculum that generates relatively uniform levels of achievement throughout the country, a nationally administered test determines university admission, and students generally enter university well prepared. University education is free, and post-graduate training includes a modest living stipend [12].

Well-educated parents tend to encourage their children to become similarly well educated, but there is much less social stratification by level of education, and much less economic disparity between those with the lowest and highest levels of education. Though the study could not pinpoint these factors as causal, it appears that Sweden may be much closer than the United States to reaching the goal of educating its population so that all receive some minimum level, and eventual attainment beyond that is more closely matched to ability, with motivation and interest likely also playing important roles in attainment in those with high IQ.

\section{Conclusion and Future Directions}

Behavior genetic modelling that recognizes and measures the possibility that genetic and environmental contributions ot variance may differ in different circumstances can provide important insights into the social impacts of the educational policies we adopt and follow. Though such studies to date are rare and definitely require replication, they are consistent with other evidence suggesting that there are substantial correlations between family background and educational outcomes, with, in the United States, those coming from more privileged family backgrounds reaching higher levels of achievement, in part at least because such families sort themselves into better educational environments.

To meet the educational goal of providing at least enough academic skills for responsible citizenry to all, the large variation in the general quality of educational environments appears to combine the worst features of (Figure 2) and (Figure 3 ), with far too much variation in educational environment. This appears to be accentuated because family background can offset the educational effects of low IQ in for some, but not for all. We clearly need to work to improve the quality of the environments available to those from less privileged family backgrounds.
The evidence for important genetic influences on intelligence is strong and we have had little success in introducing environmental interventions that produce lasting modifications in it. It is clear that those with most ability tend to benefit most from standard educational opportunities, and that those with least ability can be left behind by those same opportunities. Moreover, those with most ability can usually achieve even more with some form of educational enrichment beyond the standard curriculum. This suggests that, to help reach their potential for achievement, educational programs should be tailored to individual levels of ability.

This is difficult to implement, however, for many reasons. First, but perhaps easiest to overcome, it is expensive to develop individually tailored educational programs. It is not just the expense of implementation, but also the expense of development of different approaches that will be optimal for students of different levels of ability. Computer technology could be very helpful with such implementation though. Second, and more challenging, are the political ramifications of tailoring education to some perceived level of ability in developing children. Society is facing the same kinds of issues related to racial stereotyping and prejudice in implementing personalized medicine, and it is clear that they are difficult.

Personalized medicine is the recognition that people differ in genetic vulnerabilities to illness and in genetic responses to medications and other treatments. This recognition carries with it the idea that treatment and prevention programs should be tailored to individuals' genetic characteristics. Because we know so little about the specific genetic characteristics involved, however, present implementations of the idea rely heavily on patients' demographic characteristics, so that, for example, different blood pressure medications have been developed and prescribed for African- and European-Americans.

The sloppiness of racial distinctions makes these practices sometimes medically questionable, and the social implications of stratifying people by race for any purpose are troublesome. With respect to education the political difficulties are even greater, however, because educational attainment is so strongly associated with access to good socioeconomic prospects. Personalized education would involve the recognition that individuals differ genetically in ability to absorb information and develop skills, as well as recognition that they differ in genetic response to educational approaches.

Ultimately, it would mean individualized educational programs based on genetic differences. We have some evidence that such personalized educational programs based on some predetermined ability level might be optimal in helping students achieve as much as possible, but the longstanding debates about intelligence testing and academic tracking make clear that this would be very politically unpopular. And ironically, though we have little evidence that intelligence is very modifiable, we do have evidence that it is not helpful to think of it that way: people 
learn better when they think of ability as effort in acquiring skills and not some fixed attribute. Perhaps this is what should tell us that such formal individualized tracking programs would not work.

\section{Reference}

1. Moffitt TE, Caspi A, Harkness AR, Silva PA (1993) The natural history of change in intellectual performance: Who changes, how much, is it meaningful? Journal of Child Psychology and Psychiatry and Allied Disciplines 34(4): 455-506.

2. Plomin R, De Fries JC, McClearn GE, McGuffin P (2008) Behavioral Genetics. New York: Worth Publishers.

3. Deary IJ, Johnson W, Houlihan LM (2009) Genetic foundations of human intelligence. Human genetics 126(1): 215-232.

4. Johnson W (2007) Genetic and environmental influences on behavior: Capturing all the interplay. Psychological Review 114(2): 423-440.

5. Purcell S (2002) Variance components models for gene-environment interaction in twin analysis. Twin Research and Human Genetics 5(6): 554-571.
6. Pianta RC, Barnett WS, Burchinal M, Thornberg KL (2010) The effects of preschool education: What we know, how pulbic policy is or is not aligned with the evidence base, and what we need to know. Psychological Science in the Public Interest 10(2): 49-88.

7. Flynn JR (1987) Massive IQ gains in fourteen nations - what IQ tests really measure. Psychological Bulletin 10(2): 171-191.

8. Taylor J, Roehrig AD, Soden Hensler B, Connor CM, Schatschneider C (2010) Teacher quality moderates the genetic effects on early reading. Science 328(5977): 512-514.

9. Good RH, Kaminsky A, Smith S, Laimon D, Dill S (2001) Dynamic Indicators of Basic Early Literacy Skills, 5th Ed Eugene OR: University of Oregon.

10. Johnson W, Deary IJ, Iacono WG (2009) Genetic and environmental transactions underlying educational attainment. Intelligence 37(5): 466-478.

11. Johnson W, Deary IJ, Silventoinen K, Tynelius P, Rasmussen F (2010) Family background buys an education in Minnesota but not in Sweden. Psychological Science 21(9): 1266-1273.

12. Thurstone LL, Thurstone TG (1941) Factorial Studies of Intelligence. Chicago: University of Chicago Press.

\begin{tabular}{|l|}
\hline Your next submission with Juniper Publishers \\
will reach you the below assets \\
- Quality Editorial service \\
- Swift Peer Review \\
- Reprints availability \\
- E-prints Service \\
- Manuscript Podcast for convenient understanding \\
- Global attainment for your research \\
- Manuscript accessibility in different formats \\
( Pdf, E-pub, Full Text, Audio) \\
- Unceasing customer service \\
Track the below URL for one-step submission \\
https://juniperpublishers.com/online-submission.php \\
\hline
\end{tabular}

